\title{
Utilization of Cashew Apple Juice as a Substrate for Lactic Acid Production
}

\author{
P. Sivagurunathan*, P. Athisayakumar, C. Uma, K. Muthulakshmi and S. Satheeshkumar \\ Department of Microbiology, Faculty of Science, Annamalai University, Annamalai Nagar, Tamilnadu, India. \\ *Corresponding Author: P. Sivagurunathan, Department of Microbiology, Faculty of Science, \\ Annamalai University, Annamalai Nagar, Tamilnadu, India.
}

\begin{abstract}
The aim of this work was to utilize Cashew apple juice as a cheap substrate for the production of Lactic acid and to optimize the parameters to improve the yield. The cultures employed for Lactic acid production were isolated from different sources like Idly batter, Curd and Fruit wastes. Among the different isolates employed, the isolate LAB-I (L. casei) produced maximum $(24.4 \pm 0.52 \mathrm{~g} / \mathrm{L})$ quantity of Lactic acid. Parameter optimization was also done employing Cashew Apple Juice from yellow variety and 5 best isolates. The maximum production of Lactic Acid was observed when the pH of the fermentation media was 6.5, optimum temperature was $38^{\circ} \mathrm{C}$ and the incubation time was 3 days. Ammonium sulphate incorporation led to increase in the yield of Lactic Acid.
\end{abstract}

Keywords: cashew apple, lactic acid, LAB.

\section{INTRODUCTION}

Lactic acid has been utilized in fermentation and preservation of human foodstuffs since ancient times. In 1839, Fremy, produced lactic acid by fermentation of carbohydrates such as sucrose, lactose, mannitol, starch and dextrin. In 1881, the first commercial production of lactic acid was undertaken in the United States using microorganisms (Vijayakumar et al., 2008).

Lactic acid has been widely used in food, cosmetic, pharmaceutical and chemical industries. Since it is classified as GRAS (Generally Recognized As Safe) and permitted to be used as a food additive by the US FDA (Food and Drug Administration) (Datta et al., 1995), it is exploited in every segment of the food industry. While bacterial fermentation accounts for almost $90 \%$ of the total production of lactic acid, the rest is produced by the chemical process of hydrolyzing lactonitrile (Bulut et al., 2004). Numerous species of bacteria and a few fungi are capable of producing lactic acid by fermenting sugars. A group of bacteria named Lactic Acid Bacteria (LAB), among the lactic acid producing organisms, are commonly utilized for the production of lactic acid. Among the fungi, Rhizopus species is reported to produce lactic acid by utilizing a variety of substrates.

Agricultural residues are the most suitable substrates for microbial cultivation because they are a rich source of carbon, nitrogen and minerals and also cost less (Chagas et al., 2007). Screening for cheaper, potential agricultural raw materials is an important prerequisite before starting the fermentation process. Novel low-cost media are needed in order to improve the economics of lactic acid production by bacteria (Nancib et al., 2001). Cashew (Anacardium occidentale Linn.) an important cash crop, is grown in India in an area of 8, 20,000 ha (Nagaraja et al., 2003). Cashew, a native of South America, belongs to the Anacardiaceae family and is considered as a 'gold mine' of the wasteland as it requires low inputs for production (Attri, 2009). India is the second largest producer of cashew nut in the world after China (Costa et al., 2009).

The juice of the cashew apple, a pseudo-fruit, is rich in reducing sugars (fructose, glucose) into vitamins, minerals and some amino acids (Campos et al., 2002; Oliveira et al., 2002; Sivagurunathan et al., 2010).Cashew apple juice contains $219 \mathrm{mg}$ of vitamin $\mathrm{C}$ per portion of $100 \mathrm{ml}$, which is 5 times that of an orange and 12 times that of a pineapple. This juice also contains more magnesium $(260 \mathrm{mg})$ than oranges, bananas or pineapples. Its potassium content $(565 \mathrm{mg})$, is twice that of an orange, 4 times that of a mango and 5 times that of a pineapple (USDA, 2002). Many studies reported the functional 
properties of cashew apple juice such as anti-carcinogenic (Kubo et al., 1993), antibacterial activity against gastritis causing bacteria called Helicobacter pylori (Kubo et al., 1999; Carvalho et al., 2007), and also its anti-oxidant properties (Kubo et al., 2006).

The ultimate aim of cultivating cashew trees is for the purpose of producing cashew nuts. The nut represents $10 \%$ of the total fruit weight (Rabelo et al., 2009). The use of cashew apple as a source of high value-added sugars may represent an economic alternative (Azevedo and Rodrigues, 2000). After removing the cashew nut, the cashew apples are thrown away (or) dumped, where they undergo natural decomposition in the soil itself. While there are various reports which sought about the production of different products by utilizing cashew apple juice as a substrate, only a few reports are available that discuss its ability to produce lactic acid. With the above discussed issues related to the wastage of cashew apples and the wide application of lactic acid, the present study aims to dwell on the utilization of cashew apples as substrate, for the production of lactic acid. Optimization studies were also carried out to improve the yield of lactic acid production.

\section{Materials AND Methods}

\subsection{Collection of Sample (Cashew Apple)}

The two varieties of cashew apples, such as red (CA-R) and yellow (CA-Y), were sourced from Katchiperumal village, Ariyalur (Dist) and brought to the laboratory in clean polythene bags.

\subsection{Preparation of Cashew Apple Juice (CAJ)}

The cashew apples were washed with distilled water and the surface was sterilized in $70 \%$ (w/v) ethanol for about five seconds followed by another wash with sterile water. They were then crushed by a sterile mortar and pestle under aseptic conditions and the filtered juice was used for further analysis. The fresh juice was further clarified by adding gelatin to remove tannins. The juice was later centrifuged at 15,000 rpm for 15 minutes and supernatant was collected and stored in the refrigerator.

\subsection{Isolation and Identification of Lactic Acid Bacteria}

The LAB isolates were obtained from different sources like idly batter, milk products and fruit wastes (cashew apples) by serial dilution technique on MRS media. All lactic acid bacterial isolates were identified upto the species level by comparing their morphological, physiological and biochemical characteristics using Bergey's manual of determinative bacteriology.

\subsection{Fermentation Studies}

A loopful of culture from MRS broth was inoculated into $100 \mathrm{ml}$ of diluted cashew apple juice with added basal nutrients. The aim of inoculating the LAB isolates to cashew apple juice is to minimize the lag phase of the isolates in the fermentation media. The inoculated media were incubated at $38^{\circ} \mathrm{C}$ for about 24 to 48 hours and used as inocula for subsequent studies.

The fermentation media were designed according to the method described by Honoroto et al. (2007). LAB normally requires vitamins and minerals for their better growth which are already found in the juice of the cashew apple therefore addition of the same is not required. The $\mathrm{pH}$ of the media was adjusted to 6.5 with $\mathrm{H}_{3} \mathrm{PO}_{4}$, and the fermentation media was autoclaved at $121{ }^{\circ} \mathrm{C}$ for 15 minutes. About $10 \%$ inoculum was added to the fermentation media and the fermentation was carried out for about 2448 hours. Then the cells were removed by centrifugation at $15000 \mathrm{rpm}$ for 10 minutes. The lactic acid concentration in the supernatant was estimated by the titrimetric method using phenolphthalein as the indicator solution.

\subsection{Impact of Various Parameters on Lactic Acid Production}

To analyze the impact of various physical and chemical parameters on lactic acid production, cashew apple juice from yellow variety (CAJ-Y), and the best four LAB isolates were used in the study. Effect of nitrogen sources, $\mathrm{pH}$, temperature and incubation time were carried out as per the method described in the previous sections.

\section{Statistical Analysis}

All the tests were carried out in triplicates. The experimental data were processed statistically by applying the SPSS software, version 12.0. The critical difference was worked out at 5\% probability level for significant results $(\mathrm{P}=0.05)$. 


\section{RESUlts AND Discussion}

In our present study, cashew apple juice was utilized for the production of lactic acid using Lactobacillus isolates. They were then identified by morphological, physiological and biochemical characteristics. Among the isolates, $40 \%$ were Lactobacillus casei, 20\% Lactobacillus delbrueckii, $20 \%$ Streptococcus lactis and 20\% Leuconostoc mesenteroides. According to Karini et al. (2012), the most dominant species in dairy products was Lactobacillus casei. In the present study Lactobacillus casei was the predominant isolate.

Mallesha et al. (2010) isolated LAB from milk, curd, idly batter and pickles using pour plate technique on MRS media. They identified 16 isolates from 44 positive colonies by studying morphological, cultural, physiological and biochemical characteristics of the isolates. Hawaz (2014) isolated 9 Lactobacillus strains from curd and identified upto species level based on their physiological and biochemical characteristics.

The fermentation media was formulated by adding yeast extract and $\mathrm{K}_{2} \mathrm{H} \mathrm{PO}_{4}$ to the cashew apple juice. The juice is naturally rich in minerals and hence did not require any further addition of minerals (Veragera et al., 2010). The protein content of cashew apple juice is low (Honorato et al., 2007) but they are rich in reducing sugars, minerals and vitamins. In our present investigation, all the isolates produced lactic acid by utilizing cashew apple juice as substrate; among them 5 isolates LAB-I, II, III, IV and X produced better results. The maximum production of $24.4 \pm 0.52 \mathrm{~g} / \mathrm{L}$ was obtained from the fermentation by employing LAB-I (Lactobacillus casei) strain. Guilherme et al. (2012) reported that about $59.3 \mathrm{~g} / \mathrm{L}$ of lactic acid was produced by utilizing cashew apple juice as substrate. Silveira et al. (2010) recorded $2.36 \mathrm{~g} / \mathrm{L}$. h, of lactic acid from cashew apple juice using $L$. casei B- 442 strain.

Parameter optima are important in any type of fermentation. In the present study, various parameters like nitrogen sources, $\mathrm{pH}$, temperature, and incubation time were analyzed to find optimum conditions to increase the yield of lactic acid.

Since the nitrogen content is low in the cashew apple juice, addition of nitrogen supplements could improve the yield of lactic acid. In our present investigation, the fermentation medium was provided with different nitrogen sources. Amongst these ammonium sulfate significantly improved the yield of lactic acid (Figure 1). Aeschlimann and Stock car (1990) stated that yeast extract is considered as an essential nutrient to Lactobacilli for better production of lactic acid. Nancib et al. (2001) studied the effect of different nitrogen sources such as yeast extract, ammonium sulfate, tryptic soy, urea, peptone and casein hydrolysate on the lactic acid production in date juice containing medium using Lactobacillus casei sub sp. rhamnosus. According to them, ammonium sulfate could be a better alternative to yeast extract. Our results are in consonances with the previous, since higher production observed with ammonium sulfate incorporated medium, the lower production associated with urea incorporated medium.

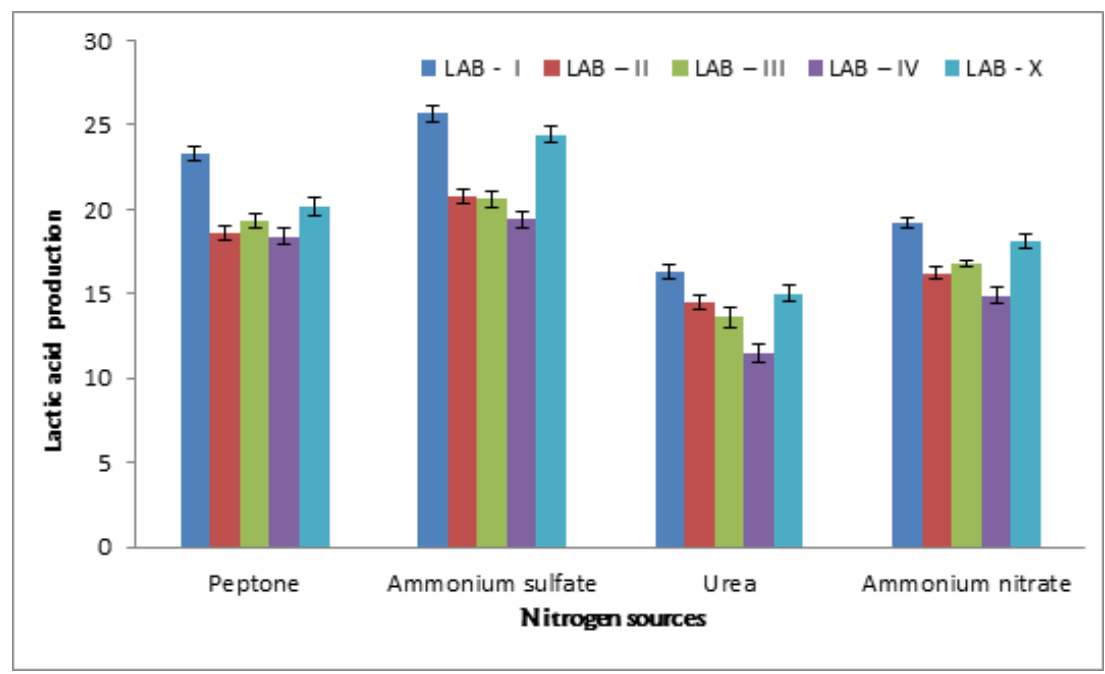

Figure1. Effect of nitrogen sources on lactic acid production

It is a well-known fact that the hydrogen ion concentration of a media will have a vital role in supporting microbial growth as well as product formation. All microorganism have their own $\mathrm{pH}$ limits, beyond which they could face stress (or) their enzymes could get affected. Such a condition ultimately results in both reduced growth and low productivity. Chooklin et al. (2011) analyzed the effect of pH control 
on lactic acid production using palmyra sap and oil palm sap supplemented with MRS media. They observed an increase in lactic acid concentration of $13 \%, 15 \%$ and $16 \%$ respectively, when the $\mathrm{pH}$ of the MRS supplemented palmyra sap and oil palm sap was controlled. The optimal $\mathrm{pH}$ for lactic acid production varies between 5.0 and 7.0. The optimal $\mathrm{pH}$ range between 5 and 6 recorded high values for both biomass and lactic acid. There have been many reports which state that a $\mathrm{pH}$ of 6.5 was optimum for lactic acid production using different lactic acid bacteria (John et al., 2006; Idris and Suzana, 2006). In the present study, the maximum production of lactic acid was observed at $\mathrm{pH} 6.5$. Above $\mathrm{pH} 7.5$, the production rate begins to decline (Figure 2).

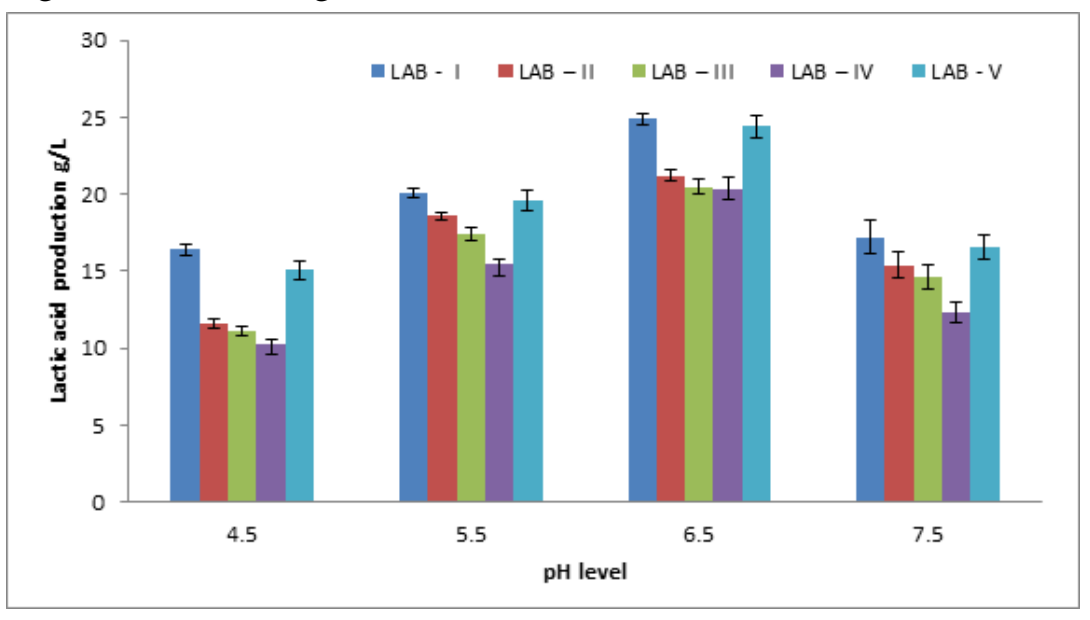

Figure2. Effect of pH on lactic acid production

Optimization of temperature is very important in any type of fermentation. Temperatures below (or) above the optimum will have a profound influence on both microbial growth and productivity. Narita et al. (2004) reported that highest yield and lactic acid mass concentration was obtained at $37^{\circ} \mathrm{C}$ employing Streptococcus bovis 148. In our findings, the isolates LAB-I, II, III and X showed highest lactic acid production at $38^{\circ} \mathrm{C}$. But in contrary, the isolate LAB-IV showed a better yield at $34^{\circ} \mathrm{C}$ (Figure $3)$.

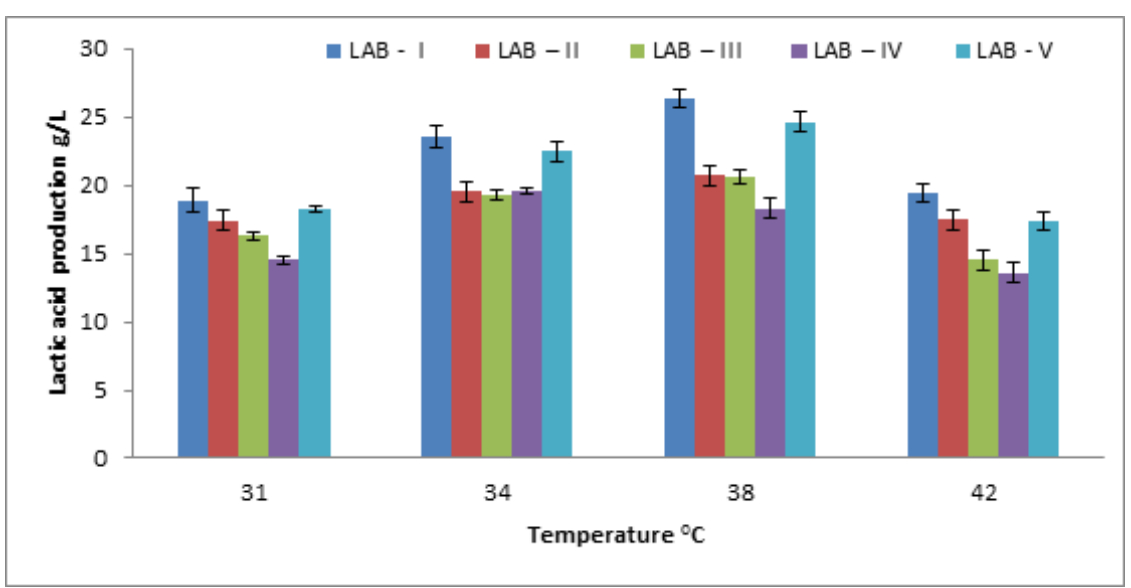

Figure3. Effect of temperature on lactic acid production in yellow cashew apple juice (CAJ-Y) supplemented media

The effect of incubation time on lactic acid production was studied. The titrable acidity was estimated for every 24 hours to find out the number of days required for maximum production of lactic acid. In all the studies, LAB-I (Lactobacillus casei) obtained from fruit wastes performed better than other LAB isolates in CAJ-Y supplemented media.Silveira et al. (2010) investigated the use of cashew apple juice as a low cost substrate for Lactobacillus casei B-442 - cultivation and production. They also analyzed the effect of reducing sugar concentration of cashew apple juice, ammonium sulfate concentration, $\mathrm{pH}$ and temperature or biomass formation, lactic acid production and productivity. The process yield was $95 \%$ when fermentation was carried out at $37^{\circ} \mathrm{C}$ with $\mathrm{pH}$ controlled at 6.5 using $\mathrm{NaOH}$. Guilherme et al. (2012) studied and modeled lactic acid by employing Lactobacillus casei B-442. The optimization of the process using the model was carried out and the optimum operating condition aiming for highest productivity, lowest production cost and highest gross profit are presented. They also reported that the highest production of lactic acid $(59.3 \mathrm{~g} / \mathrm{L})$ was obtained from cashew apple juice. 


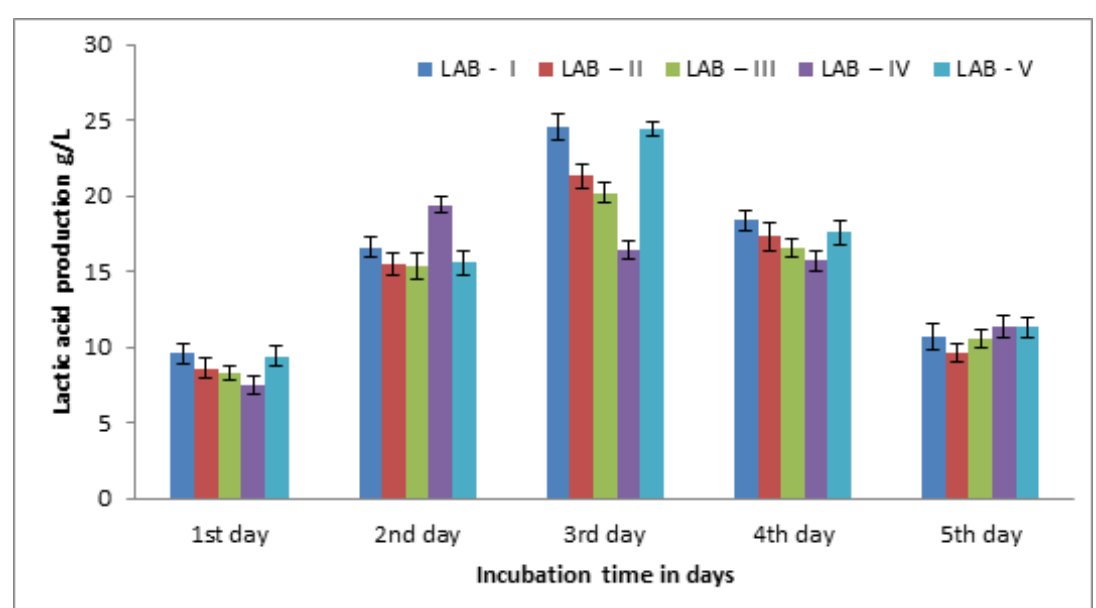

Figure4. Effect of incubation time on lactic acid production in cashew apple juice supplemented media

\section{CONCLUSION}

Extensive research is being conducted to screen low cost substrates to produce various products through fermentation. Utilization of agriculture residues as substrates might not only cut down fermentation costs but also minimize environmental pollution. Large amount of cashew apples are dumped in the land after removing the cashew nuts. Though cashew apples can be consumed as juice, ice cream and food stuffs, many studies have proved that cashew apple juice could be an ideal medium for the growth of microorganisms. Such an attribute can be used efficiently for producing industrially valuable products through fermentation. The result of the study implies that cashew apple juice can be effectively utilized as a substrate for lactic acid production. The study also paves the way for cashew apple waste disposal problems and also producing the most valuable organic acid using an economically feasible method.

\section{REFERENCES}

[1] Aeschlimann, A. and Stockar, V.U. (1990). The effect of yeast extract supplementation on the production of lactic acid from whey permeate by Lactobacillus helveticus. Biotechnology Letters. 32(4): 398-402.

[2] Attri, B.L. (2009). Effect of initial sugar concentration on the physico-chemical characteristics and sensory qualities of cashew apple wine. Natural Product Radiance. 8: 374-379.

[3] Azevedo, D.C.S. and Rodrigues, A.E. (2000). Obtainment of high-fructose solutions from cashew (Anacardium occidentale) apple juice by simulated moving-bed chromatography. Sep. Sci. Technol. 35 : 2561-2581.

[4] Bulut, S., Elibol, M. and Ozer, D. (2004). Effect of different carbon sources on L (+)-lactic acid production by Rhizopus oryzae. Biochemical Engineering Journal. 21(1): 33-37.

[5] Campos, D.C.P., Santos, A.S., Wolkoff, D.B., Matta, V.M., Cabral, L.M.C. and Couri, S. (2002). Cashew apple juice stabilization by microfilteration. Desaltination. 148: 61-65.

[6] Carvalho, J.M., Maia, G.A., Figueiredo, R.W., Brito, E.S. and Rodriguese, S. (2007). Development of a blended nonalcoholic beverage composed of coconut water and cashew apple juice containing caffeine. J. Food Quality. 30: 664-681.

[7] Chagas, C.M.A., Honorato, T.L., Pinto, G.A.S., Maia, G.A. and Rodrigues, S. (2007). Dextransucrase production using cashew apple juice as substrate: effect of phosphate and yeast extract addition: Bioprocess. Biosyst. Eng. 30: 207-215.

[8] Chooklin, S., Kaewsichan, L. and Kaewsichan, J. (2011). Potential use of Lactobacillus casei TISTR 1500 for the bioconversion from palmyra sap and oil palm sap to lactic acid. Electronic Journal of Biotechnology. 14(5): 1-13.

[9] Costa, J.M.C., Felipe, F.M.F., Maia, G.J., Hernandez, F.F.F and Brasil, L.M. (2009). Production and characterization of the cashew apple (Anacardium occidentale L.) and guava (Psidiumguajava I.) fruit powder. J. Food Process. Preserv. 33: 299-312.

[10] Datta, R., Tsai, S.P., Bonsignore, P., Moon, S.H. and Frank, J.R. (1995). Technological and economic potential of poly (lactic acid) and lactic acid derivatives. FEMS Microbiol. Rev. 16: 221231.

[11] Guilherme, A., Silveira, M., Fontes, C., Rodrigues, S. and Fernandes, F. (2012). Modeling and optimization of lactic acid production using cashew apple juice as substrate. Food Bioprocess Technol. 5(8): 3151-3158. doi: 10:1007/sl 1947-011-0670-z. 
[12] Hawaz, E. (2014). Isoaltion and identification of probiotic lactic acid bacteria from curd and invitro evaluvation of its growth inhibition activities against pathogenic bacteria. Afr. J. Microbiol. Res. 8(13): 1419-1425.

[13] Honorato, T.L., Rabelo, M.N., Pinto, G.A.S and Rodrigues, S. (2007). Production of lactic acid and dextran using cashew apple juice as a substrate. Cienc. Techol. Aliment. Campainas. 27: 254-258.

[14] Idris, A and Suzana, W. (2006). Effect of sodium alginate concentration, bead diameter, initial pH and temperature on lactic acid production from pineapple waste using immobilized Lactobacillus delbrueckii. Process Biochem. 41: 1117-1123.

[15] John, R.P., Nampoothin, K.M. and Pandey, A. (2006). Solid-State fermentation for L-lactic acid production from agro wastes using Lactobacillus delbrueckii. Process Biochem. 41: 759-763.

[16] Karini, R., Mortazarian, A.M. and Amiri-Rigi, A. (2012). Selective enumeration of probiotic microorganisms in cheese. Food Microbiol. 29: 1-9.

[17] Kubo, I., Ochi, M., Vieria, P.C. and Komatsu, S. (1993). Antitumor agents from the cashew (Anacardium occidentale) apple juice. J. Agri. Food Chem. 41: 1012-1015.

[18] Kubo, J., Lee, J.R. and Kubo, I. (1999). Anti-Helico bacter pylorin agents from the cashew apple. J. Ari. Food Chem. 47: 533-537.

[19] Kubo, I., Masuoka, N., Ha, T.J. and Tsuijimoto, K. (2006). Antioxidant activity of anacardic acids. Food Chem. 99: 555-562.

[20] Mallesha, R., Shylaja, D., Selvakumar, D and Jagannath, J.H. (2010). Isolation and identification of lactic acid bacteria from raw and fermented products and their antibacterial activity. Rec. Res. Sci. Tech. 2: 4246.

[21] Nagaraja, K.V., Bhuvaneshwari, S. and Swamy, K.R.M. (2003). Biochemical characterization of cashew (Anacardium occidentale L.) apple juice and pomace in India. PGR Newsletter. Issue No. 149: 9-13.

[22] Nancib, N., Nancib, A., Boudjelal, A., Benslimane, C. and Blanchard F. (2001). The effect of supplementation by different nitrogen sources on the production of lactic acid from date juice by Lactobacillus casei sub sp. rhamnosus. Bioresource Technol. 78: 149-115.

[23] Narita, J., Nakahara, S., Fukuda, H. and Kondo, A. (2004). Efficient production of L(+)-Lactic acid from raw starch by Streptococcus bovis 148. J. Biosci. Bioeng. 97: 423-425.

[24] Oliveira, J.S., Ferreira, R.P., Cruz, C.D., Pereira, A.V., Botrel, M.A., Von Pinho, R.G., Rodrigues, J.A.S., Lopes, F.C.F. and Miranda, J.E.C. (2002). Adaptabilidadee Estabilidadeem Cultivares de Sorgo. Revista Brasileira Zootecnia. 31(2): 883-889.

[25] Rabelo, M.C., Fontes, C.P.M.L. and Rodrigues, S. (2009). Enzymes synthesis of oligosaccharides using cashew apple juice as substrate. Biores. Technol. 100: 5574-5580.

[26] Silveira, M.S., Fontes, C.P.S., Guilherme, A.A., Fernandes, A.N. and Rodrigues, S. (2010). Cashew apple juice as substrate for lactic acid production. Food and Bioprocess Technology. 5: 947-953.

[27] Sivagurunathan, P., Sivasankari, S. and Muthukaruppan, S.M. (2010). Characterization of cashew apple (Anacardiumoccidentale L.) fruits collected from Ariyalur District. J. Biosci. Res. 1: 101-107.

[28] USDA-United States Department of Agriculture (2002). Nutrition Database for Standard Reference. Washington.

[29] Veragera, C.M.D.A.C, Honorato, T.L., Maia, G.A. and Rodrigues, S. (2010). Pre-biotic effect of fermented cashew apple (Anacardium occidentale L.) juice LWT. Food Science and Technology. 43: 141-145.

[30] Vijayakumar, J., Aravindan, R. and Viruthagiri, T. (2008). Recent trends in the production, purification and application of lactic acid. Chem. Biochem. Eng. Q. 22(2): 245-264.

Citation: P. Sivagurunathan et al., "Utilization of Cashew Apple Juice as a Substrate for Lactic Acid Production", International Journal of Research Studies in Biosciences (IJRSB), vol. 6, no. 4, pp. 1-6, 2018. http://dx.doi.org/10.20431/2349-0365.0604001

Copyright: (C) 2018 Authors. This is an open-access article distributed under the terms of the Creative Commons Attribution License, which permits unrestricted use, distribution, and reproduction in any medium, provided the original author and source are credited. 